\title{
Modeling of Progressive Circumferential Heating of Cylindrical Objects with Double Heat Source
}

\begin{abstract}
T. DOMAŃSKI
Czestochowa University of Technology, 42-201 Czestochowa, Poland

Doi: $10.12693 /$ APhysPolA.138.305

*e-mail: domanski@imipkm.pcz.pl

The work describes the physical aspects of modeling the heat source movement around the perimeter and its proposed distributions. This study concerns numerical modelling of thermal phenomena in spiral laser heating of shaft made steel. Numerical 3D analysis is developed for the prediction of heat affected zone in Abaqus/FEA software. Power distribution of spirally moving double heat source is implemented into additional DFLUX subroutine, written in Fortran programming language. The model of heat source motion takes into account the size of heat affected zone. Results of numerical analysis include temperature field, predicted heat affected zone and cooling rates. These results are a start point for the analysis of thermomechanical phenomena with the consideration of phase transformations in solid state.
\end{abstract}

topics: heating, Abaqus, heat source distribution

\section{Introduction}

The paper presents the results of numerical simulations of surface peripheral heating with a double heat source simulating laser heating. The material of the heated cylinder is carbon steel with increased strength S355. Numerical tests were carried out in the Abaqus FEA calculation program. The program developed a discrete model of the analyzed heated zone. In the material module of the Abaqus/CAE program, thermal properties variable with temperature were defined. The implementation of additional numerical procedures enabled modeling of the laser beam movement around the perimeter of the object. Based on the numerical calculation the temperature distribution in the heated zone was determined. The shape of the remelting zone and heat affected zone was estimated numerically.

\section{Mathematical and numerical model}

The heat flow equation in the Abaqus program is made on the basis of the energy conservation equation and Fourier law, expressed in the criterion of weighted residuals method. The notation of the equation in the program is as follows [1]:

$$
\begin{gathered}
\int_{V} \rho \frac{\partial U}{\partial t} \delta T \mathrm{~d} V+\int_{V} \frac{\partial \delta T}{\partial x_{\alpha}}\left(\lambda \frac{\partial T}{\partial x_{\alpha}}\right) \mathrm{d} V= \\
\int_{V} \delta T q_{V} \mathrm{~d} V+\int_{S} \delta T q_{S} \mathrm{~d} S,
\end{gathered}
$$

where $\lambda\left[\mathrm{W} /\left(\mathrm{m}{ }^{\circ} \mathrm{C}\right)\right]$ is a thermal conductivity, $V$ is a volume $\left[\mathrm{m}^{3}\right], S$ is a surface $\left[\mathrm{m}^{2}\right]$, while $q_{V}\left[\mathrm{~W} / \mathrm{m}^{3}\right]$ and $q_{S}\left[\mathrm{~W} / \mathrm{m}^{2}\right]$ denote a laser beam heat source and a boundary heat flux, respectively. Further, $U=U(T)[\mathrm{J} / \mathrm{kg}]$ is an internal energy, $T=$ $T\left(x_{\alpha}, t\right)\left[{ }^{\circ} \mathrm{C}\right]$ is temperature, $\delta T$ is a variational function, and $\rho\left[\mathrm{kg} / \mathrm{m}^{3}\right]$ is a density.

Above equation is completed by the initial conditions and boundary conditions of Dirichlet and Neumann types. The heat exchange with the environment is performed by Newton's condition, which takes into account the loss of heat by convection, radiation and evaporation $[1,2]$.

Most often in the literature on the numerical modeling of the laser beam hardening process to describe the power distribution of the welding source, the Gaussian mathematical model of the volumetric heat source is adopted (2). This model takes into account the linear decrease of energy intensity along material penetration depth [2]. The shape of heat source is assumed as the shape of a truncated cone (Fig. 1) [3], namely

$$
q_{V}(r, z)=\frac{Q}{\pi r_{0}^{2} h} \exp \left(1-\frac{r^{2}}{r_{0}^{2}}\right)\left(1-\frac{z}{h}\right),
$$

where $Q[\mathrm{~W}]$ is a laser beam power, $h[\mathrm{~m}]$ is the laser heat source penetration depth, $z[\mathrm{~m}]$ is actual depth, $r_{0}$ is a beam radius. The actual radius $r[\mathrm{~m}]$ is defined as $r=\sqrt{x^{2}+y^{2}}$.

In Abaqus FEA, the moveable heating source is simulated using an additional DFLUX numerical subroutine written in the Fortran programming language [1]. The subroutine takes into account 


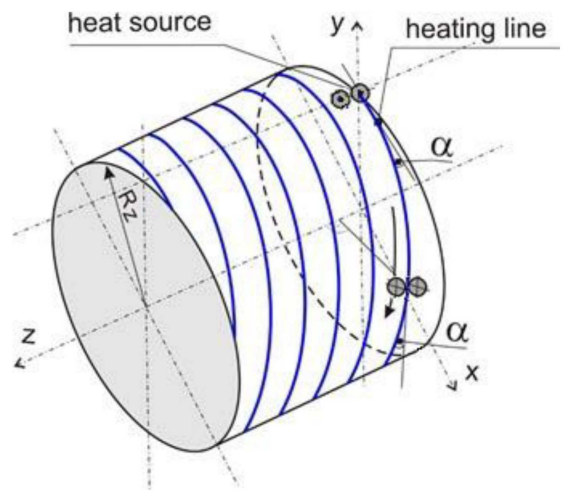

Fig. 1. Diagram of the analyzed object.

the power distribution of the beam, its location, beam translation and motion direction. The location of the center of the double source is determined for each time step depending on the adopted source velocity.

The three-dimensional discrete model of the analyzed object was developed in the Abaqus FEA calculation program. The discrete model analyzed and its division into finite elements is shown in Fig. 1. The object under consideration is a shaft with a diameter of $60 \mathrm{~mm}$ made of S355 steel.

The work analyzes the impact of heat source movement parameters on the size of a heated zone. Technological parameters of the heating process were taken from the literature [3, 4] for numerical calculations. For the heating process the following was assumed: beam power $Q=600 \mathrm{~W}$ and source velocity $v=1 \mathrm{~m} / \mathrm{min}$.

Based on the numerical verification in the case of heating, the beam radius $r=0.9 \mathrm{~mm}$, and the penetration depth $h=2 \mathrm{~mm}$. The distance between adjacent heat sources was $3 \mathrm{~mm}$.

The location of the heating source on the outer surface of the shaft depends on the adopted heating velocity and time. The analysis is carried out in polar coordinates transposed into the Cartesian system. Therefore,

$$
\left\{\begin{array}{l}
x=R_{z} \sin \left(\phi_{0}+\omega t\right) \\
y=R_{z} \cos \left(\phi_{0}+\omega t\right) \\
z=z_{0}+v_{2} t
\end{array}\right.
$$

where $R_{z}[\mathrm{~m}]$ is an outer radius of the shaft, $\phi_{0}$ is the angle of the initial position of heat source on the outer shell, $\omega=v_{1} t$ is the angular velocity, where $v_{1}=$ const is a peripheral velocity and $t[\mathrm{~s}]$ means time. The initial position on the axis $z$ is denoted as $z_{0}$, while $v_{2}$ is an axial velocity along the $z$ axis. The heating velocity $v$ results from contribution of both the peripheral $v_{1}$ and axial $v_{2}$ velocity, namely $v=\sqrt{v_{1}+v_{2}}$.

Figure 2 shows the numerical model with a finite element grid marked on it. The highest mesh density occurs at the place of operation of the heating source. To reduce the duration of the simulation at a further distance from the heating line, the mesh

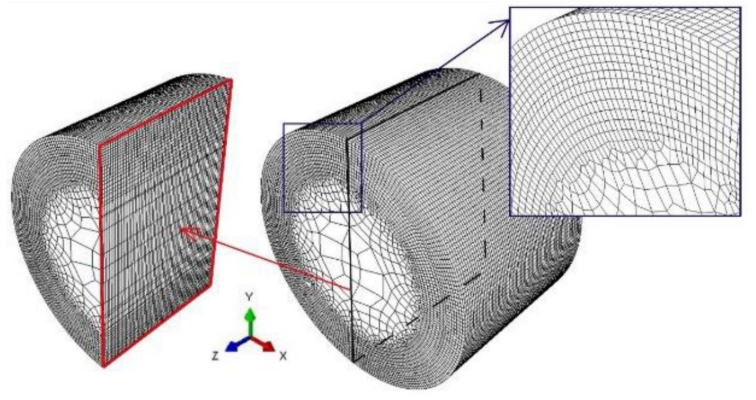

Fig. 2. Finite element mesh.

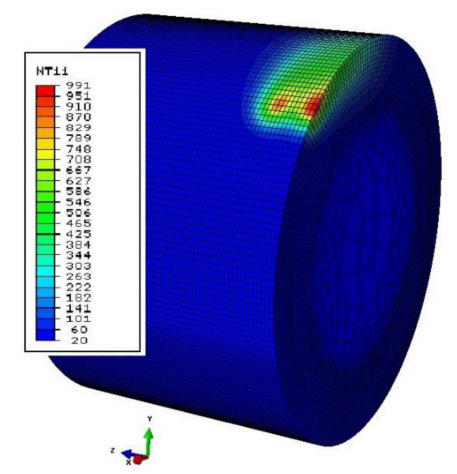

Fig. 3. The temperature distribution on the side surface of the shaft.

should have much larger dimension. Numerical calculations were performed using a separable method. At first calculations of thermal phenomena were made followed by calculations of structural and mechanical phenomena.

Numerical analysis of thermal phenomena occurring in the hardening process is difficult to perform because it requires taking into account the specific conditions of the laser beam heating process.

The 355 steel material model was included in the Abaqus material module. Calculations took into account dependence of variables on temperature, thermomechanical properties of the adopted steel grade [5-7]. For 355 steel one has solidus temperature $T_{S}=1400^{\circ} \mathrm{C}$, liquidus temperature $T_{L}=1455^{\circ} \mathrm{C}$, and the latent heat of fusion $H_{L}=260 \times 10^{3}[\mathrm{~J} / \mathrm{kg}]$. The ambient temperature is $T_{0}=20^{\circ} \mathrm{C}$ and the heat transfer coefficient with the environment is equal $\alpha_{k}=100 \mathrm{~W} / \mathrm{m}^{2}$.

\section{Results and discussion}

Temperature distribution was determined for the analyzed heating technique and the shape and size of remelting zones was determined. Simulation calculations were performed on the basis of developed numerical models for the adopted process parameters. In Figs. 3 and 4, a solid line indicates the $\mathrm{A}_{c 3}$ temperature exceeding limits.

Based on presented the results (Fig. 4), it can be concluded that the shaft surface has been heated to a depth of $2.3 \mathrm{~mm}$ (temperature above $1000^{\circ} \mathrm{C}$ ), 


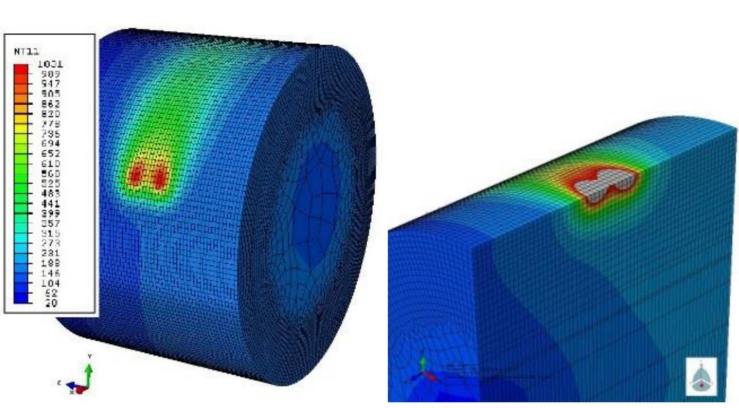

Fig. 4. Temperature distribution on the lateral surface of the shaft after time $48 \mathrm{~s}$ and in crosssection.
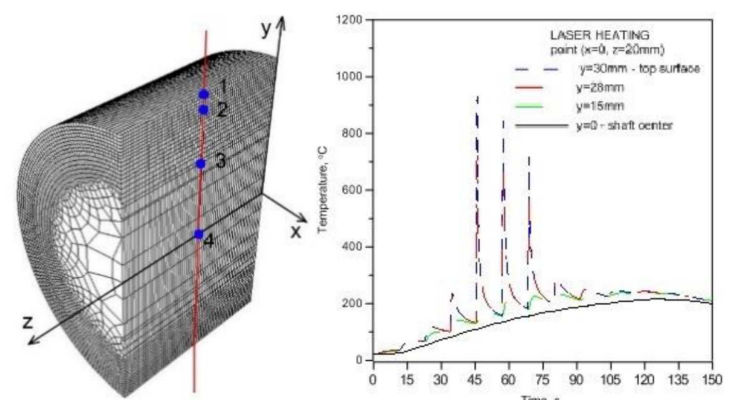

Fig. 5. Longitudinal temperature distribution in points $1,2,3,4$.

which is the temperature that guarantees the transformation of the structure into austenite. The shaft core was also heated to around $180^{\circ} \mathrm{C}$, which does not change its structure.

Figure 5 presents thermal cycles for 4 selected measuring points located in the middle of the length of the heated shaft. Selected points are located at different distances from the symmetry axis as shown in the figure.

\section{Conclusions}

Numerical simulation of hardening process is Abaqus program requires implementation of additional numerical subroutines. Based on the developed model, it is possible to estimate the temperature distribution in spirally hardened shafts of any diameter, which allows forecasting the surface properties of hardened objects. The presented results are the basis for the development of the model that allows estimation of phase transformations and mechanical properties of hardened objects. During the analysis, the adopted parameters of the heating source simulating laser heating allow achieving appropriate temperature distributions enabling hardening of the shaft surface layer at a depth of $2 \mathrm{~mm}$. Developed mathematical and numerical models in Abaqus software enable the analysis of thermal and mechanical phenomena occurring during laser hardening, give the possibility of numerical prediction of temperature field and the geometry of heating source. The use of a dual source of heat has allowed synergy of thermal energy and increased heating efficiency.

\section{References}

[1] SIMULIA 2007 Abaqus FEA theory manual, Ver. 6.7, Dassault System.

[2] T. Domański, A. Sapietova, M. Saga, Procedia Eng. 177, 64 (2017).

[3] P.M. Pacheco, M.A. Savi, A.F. Camarao, J. Strain Analysis 36, 507 (2001).

[4] H. Cheng, J. Xie, J. Li, Comput. Mater. Sci. 29, 453 (2004).

[5] A. Arif, A. Al-Omari, B. Yilbas, Y. Al-Nassar, J. Mater. Process. Technol. 211, 675 (2011).

[6] W. Piekarska, M. Kubiak, Z. Saternus, S. Stano, T. Domański, Arch. Metall. Mater. 60, 1965 (2015).

[7] Z. Saternus, W. Piekarska, Procedia Eng. 177, 196 (2017). 